\title{
PERCEPÇÕES DE PRECONCEITO POR FAMILIARES DE CRIANÇAS COM TRANSTORNO DO ESPECTRO AUTISTA
}

\section{Max Amaral Balieiro'; Ana Vitória dos Santos Menezes'; Érika Tatiane de Almeida Fernandes Rodrigues $^{2}$; Samea Marine Pimentel Verga ${ }^{3}$}

${ }^{1}$ Graduando de Bacharelado em Enfermagem, Universidade Federal do Amapá (UNIFAP), Macapá, Amapá.

${ }^{2}$ Doutora em Ciências - USP, Universidade Federal do Amapá (UNIFAP), Macapá, Amapá.

${ }^{3}$ Doutoranda do Programa de Pós-graduação em Enfermagem da Universidade Federal do Paraná (PPGENF/UFPR); Mestre em Ciências da Saúde - UNIFAP.

\section{DOI: 10.47094/IICNNESP.2021/38}

\begin{abstract}
RESUMO
Objetivos: Identificar relatos de preconceito nas entrevistas obtidas com os familiares de crianças diagnosticadas com transtorno do espectro autista no estado do Amapá. Metodologia: Estudo descritivo, com abordagem qualitativa, realizado através da análise de 29 entrevistas semiestruturadas, com coleta realizada nos anos de 2018 e 2019 em famílias de crianças autistas assistidas em um centro de apoio à crianças com necessidades especiais em Macapá-Ap. Resultados: constatouse frequentemente relatos de preconceito nas entrevistas analisadas, sendo que algumas famílias evidenciaram o preconceito sofrido pelas crianças no meio social externo e no meio familiar. Conclusão: identificou-se preconceito pelos familiares de crianças autistas no círculo familiar e nos círculos sociais externos, o que inclui escolas e áreas como, praças, shoppings e parques. Dessa maneira, evidencia-se a necessidade de a sociedade conhecer e principalmente respeitar as crianças, sobretudo as com necessidades especiais, para que dessa forma preceitos sejam modificados e ressignificados para um melhor convívio.
\end{abstract}

PALAVRAS-CHAVE: Autismo. Preconceito. Família.

ÁREA TEMÁTICA: Outros.

\section{INTRODUÇÃO}

O autismo, chamado de Transtorno de Espectro Autista (TEA) é classificado como um transtorno global do neurodesenvolvimento, que se manifesta ainda na infância, caracterizado por déficits que atrasam o desenvolvimento pessoal, social, educacional ou profissional (American Psychiatric Association, 2013). Logo, uma criança portadora desse transtorno apresenta comportamentos que diferem do padrão social normal, o que pode favorecer o preconceito dentro e fora do âmbito familiar. O objetivo do presente estudo é identificar se há preconceito pela percepção das famílias de crianças autistas estudadas. 


\section{METODOLOGIA}

Trata-se de um estudo qualitativo, realizado com 29 familiares de crianças autistas, assistidas no Centro Raimundo Nonato no município do Amapá. A coleta ocorreu entre novembro de 2018 a março de 2019 através de entrevistas semiestruturadas cujos os dados foram submetidos à análise de conteúdo. Este estudo está em consonância com a Resolução n. 0466/2012 do Conselho Nacional de Saúde (CNS) /MS e foi aprovado pelo Comitê de Ética em Pesquisa sob o parecer consubstanciado n. 2.327.633.

\section{RESULTADOS E DISCUSSÕES}

Ao analisar-se as entrevistas, pode-se perceber que frequentemente os familiares afirmaram sentir o preconceito de maneira geral para com sua criança, tanto de dentro do âmbito familiar quanto fora deste, ocorreram situações de cunho preconceituoso, podendo-se citar neste caso, a escola ou ainda áreas de lazer como parques, shoppings e praças.

Este resultado pode ser identificado nos seguintes trechos retirados de algumas das entrevistas:

\footnotetext{
“a gente passa por questão de preconceito às vezes na rua né” (Mãe 2)

"meu esposo que não aceitou ainda" (Mãe 28)

“já sofri muito, muito preconceito” (Mãe 29)
}

\section{CONSIDERAÇÕES FINAIS}

Conclui-se que infelizmente o preconceito sofrido pelas crianças autistas e seus familiares está presente e que os dados obtidos das entrevistas revelam também que este preconceito se aplica não somente a pessoas de fora do círculo social da criança, mas que também têm raízes no seio familiar.

Foi constatado que existem fatores psicossociais que podem vir a atuarem como fatores protetivos ou que causam impactos negativos na saúde mental materna, portanto, a falta de suporte social e conjugal são fatores que podem vir a representar um problema neste aspecto tão importante do cuidador (MEIMES et al., 2015). Logo, a existência de preconceito nessas redes de apoio, pode causar riscos para o bem-estar geral da família, o que pode futuramente comprometer a continuidade do tratamento da criança.

Apesar das campanhas de conscientização sobre o TEA, ainda é imprescindível destacar a necessidade de um maior esclarecimento do autismo para a população geral, uma vez que grande parte do preconceito nasce do desconhecimento acerca do transtorno e de suas nuances, para que dessa forma num futuro não tão distante estas barreiras criadas pelo preconceito, sejam rompidas. 


\section{PRINCIPAIS REFERÊNCIAS}

1. American Psychiatric Association. (2013). Diagnostic and statistical manual of mental disorders (5th ed.). Arlington, VA: American Psychiatric Publishing.

2. MEIMES, M. A., Saldanha, C. H., \& Bosa, A. C. (2015). Adaptação materna ao transtorno do espectro autismo: Relações entre crenças, sentimentos e fatores psicossociais. Psico, 46(4),412422. Disponível em: https://dialnet.unirioja.es/descarga/articulo/5632992.pdf. Acesso em: 2 jun. 2021. 